Review

\title{
Direct Energy Supply to the Reaction Mixture during Microwave-Assisted Hydrothermal and Combustion Synthesis of Inorganic Materials
}

\author{
Roberto Rosa *, Chiara Ponzoni and Cristina Leonelli \\ Dipartimento di Ingegneria "Enzo Ferrari”, Università degli Studi di Modena e Reggio Emilia, via \\ Vignolese 905/A, 41125 Modena, Italy; E-Mails: chiara.ponzoni@unimore.it (C.P.); \\ cristina.leonelli@unimore.it (C.L.)
}

* Author to whom correspondence should be addressed; E-Mail: roberto.rosa@unimore.it; Tel.: +39-59-205-6224; Fax: +39-59-205-6243.

Received: 22 November 2013; in revised form: 23 January 2014 / Accepted: 28 April 2014 /

Published: 5 May 2014

\begin{abstract}
The use of microwaves to perform inorganic synthesis allows the direct transfer of electromagnetic energy inside the reaction mixture, independently of the temperature manifested therein. The conversion of microwave (MW) radiation into heat is useful in overcoming the activation energy barriers associated with chemical transformations, but the use of microwaves can be further extended to higher temperatures, thus creating unusual high-energy environments. In devising synthetic methodologies to engineered nanomaterials, hydrothermal synthesis and solution combustion synthesis can be used as reference systems to illustrate effects related to microwave irradiation. In the first case, energy is transferred to the entire reaction volume, causing a homogeneous temperature rise within a closed vessel in a few minutes, hence assuring uniform crystal growth at the nanometer scale. In the second case, strong exothermic combustion syntheses can benefit from the application of microwaves to convey energy to the reaction not only during the ignition step, but also while it is occurring and even after its completion. In both approaches, however, the direct interaction of microwaves with the reaction mixture can lead to practically gradient-less heating profiles, on the basis of which the main observed characteristics and properties of the aforementioned reactions and products can be explained.
\end{abstract}


Keywords: energy transfer; microwaves; hydrothermal synthesis; combustion synthesis; nanomaterials

\section{Introduction}

For many years, the most widely used method for the preparation of oxides, chalcogenides, silicides and carbides was the direct solid-state reaction between powders, and it probably still represents the most widespread approach for the large-scale production of these important inorganic materials [1,2].

The main limitation of solid-state syntheses, with respect to those exploiting molecular precursors (i.e., those occurring in the liquid or gaseous phases), is the difficulty in bringing the different reactants sufficiently close to each other to allow optimum reduction of diffusion paths. In the solid state, the diffusion limitation is usually compensated by employing high temperatures and long heating periods. These conditions do not permit a subtle control of the reaction stoichiometry nor is it possible to synthesize thermally labile or metastable compounds [2]. The use of microwave (MW) energy, which was initially applied in inorganic chemical synthesis in these same solid-state ceramic routes, allows a significant reduction of the reaction times. This advantage is mainly due to the direct interaction of the electromagnetic field with the inorganic solid reactants, that is the typical feature of volumetric heating. In early studies, when temperature measurement was not properly conducted during microwave irradiation, an additional feature such as lowering of reaction temperatures, with respect to the conventionally performed syntheses [3-9], was reported. However, more accurate experimental set-ups demonstrated that a correct temperature measurement did not confirm this latter observation, while the possibility of obtaining metastable phases was confirmed [5].

With the discovery of the quantum size effect [10,11], solid state synthetic approaches started to be disregarded for the synthesis of advanced inorganic compounds, since engineered nanomaterials rapidly became the main object of study for material scientists and inorganic chemists worldwide [12]. Indeed, the extremely harsh synthetic conditions typical of solid-state synthesis excluded any possibility of a precise control of particle size and shape. An accurate process control, even in non-equilibrium conditions, is fundamental in order to pave the way towards new and exciting advanced applications. Extremely large surface areas and the ability to be functionalized are additional appealing characteristics of engineered nanomaterials. Soft chemistry solution routes $[13,14]$ were consequently performed and investigated in order to explore the different possibilities offered by building desired nanostructures via an almost atom-by-atom assembly (bottom-up approach), rationally designing the final product using reaction mechanism considerations (with similarity to the approach of organic chemists). These synthetic strategies include, but are not limited to, sol-gel [15-19], hydrothermal (more generally solvothermal) [20-24] and the most recently developed solution combustion synthesis [25-31]. By analogy to the evolution seen in solid state ceramic synthesis (as briefly discussed above), and later in organic chemistry [32-37], microwave energy started to be applied in these wet-chemical inorganic syntheses, even if in most of the cases it was considered a mere tool to significantly reduce the reaction times. On the other hand, although much more sporadically than what had occurred for organic syntheses, several additional advantages and characteristics arising from the use of microwave energy 
were also reported and claimed in the inorganic chemistry field [38]. The most frequently observed feature found when applying microwave heating in a chemical reactor is the resulting uniform particle size distribution; additionally, an effect of the magnetic field on particle morphology has been detected under microwave assisted syntheses of magnetic particles.

The aim of the present work is to focus on these aspects of microwave-assisted inorganic synthesis of engineered nanomaterials, highlighting the main differences that characterize the product obtained with respect to conventional synthesis methods. Results are expected to explain the observed differences on the basis of the microwaves' intrinsic property of being based on a pure energy transfer mechanism rather than heat transfer. Particularly, microwave-assisted hydrothermal synthesis and microwave-assisted combustion synthesis techniques probably represent the most significant examples that can highlight such differences related to the synthetic route. The reason for this is twofold. Firstly, the aqueous medium characterizing both techniques represents one of the most favorable environments for performing microwave-assisted reactions (also approaching a green chemistry perspective [39]). Secondly, both of these syntheses are characterized by synthetic and reactive conditions barely accessible by using conventional heating. Indeed, these adverse conditions can be emphasized by the presence of thick pressurized reaction vessels (utilized in hydrothermal synthesis) and highly exothermic reaction fronts (occurring during combustion syntheses), which in turn make it extremely difficult to transfer heat through the walls of the reactor or to continue to transfer energy after the ignition of the self sustaining reaction.

Even if, nowadays, hydrothermal synthesis has practically reached an optimal, well recognized level of controllability and versatility in the formation of a wide choice of nanostructures [40,41], nevertheless the advantages resulting from the use of microwaves as an innovative energy source need yet to be fully reviewed, especially those which are not related to a mere reduction of reaction time. Moreover, considerations of the scalability of microwave-assisted hydrothermal synthesis, of the possible continuous flow equipment and the resulting process intensification perspectives of this technology will be covered in the next sections. On the other hand, solution combustion synthesis probably represents the most innovative inorganic synthetic strategy, at least for obtaining oxide-based nanostructures. Surely, its intrinsic energy saving characteristics constitute the main attraction of this synthesis approach, and its poor ability to tailor the size and the shape of the target product also represents the main limitation and the main research challenge, to which the application of microwave energy could furnish a partial solution or at least stimulate new findings.

After a brief summary of the fundamentals of microwave energy transfer mechanisms, the next sections will be devoted to an overview of recent advances in microwave-assisted hydrothermal and microwave-assisted solution combustion synthesis for the production of selected engineered nanomaterials, with particular focus on the innovative features characterizing these techniques, which result from both the energy source employed and the synthetic approach used. 


\section{Microwave Energy Transfer Fundamentals}

As is well known, the electromagnetic energy in the microwave band is characterized by frequencies between $300 \mathrm{MHz}$ and $300 \mathrm{GHZ}$, corresponding to wavelength values of approximately $1 \mathrm{~m}$ and $1 \mathrm{~mm}$, respectively, and a photon energy between $1.24 \times 10^{-6}$ and $1.05 \times 10^{-2} \mathrm{eV}$, respectively. Microwave heating fundamentally differs from conventional heating mechanisms in that the former is directly generated in the materials by the interaction of the electromagnetic field with electric and magnetic dipoles, which account for the material dielectric, electric and magnetic properties [42].

In the case of aqueous saline solution, the main subject of this review paper, the magnetic field effects on the heating mechanism can be easily neglected. Thus, the interaction of the applied alternating electromagnetic field with the reactive aqueous solution will be uniquely related to its dielectric properties as well as solution conduction.

The ability of a particular dielectric material to polarize in the presence of an applied electric field defines its permittivity (also known as dielectric constant), $\varepsilon^{\prime}$, which can be used to describe the response of the material to the electric field. Polarization phenomena involve dipoles, ions, electrons and interfaces, all of which contribute to the permittivity. In order to account for the alternating nature of the sinusoidal electric field applied (thus for the frequency-dependant nature of the dielectric constant), and for the consequent losses, which are derived from the unavoidable phase shift occurring between the polarization and the electric field, which is responsible for heating, the complex permittivity $\varepsilon^{*}$ must be introduced according to the following Equation 1 [43]:

$$
\varepsilon^{*}=\varepsilon-j \varepsilon=\varepsilon_{0}\left(\varepsilon_{r}-j \varepsilon_{r}\right)
$$

where $\varepsilon_{0}$ represents the free space permittivity, while the index " $r$ " is referred to values relative to the corresponding empty space values. The imaginary part $\varepsilon$ " represents the so-called loss factor, which is related to the ability of the material to store energy.

The ratio between the real and the imaginary parts of the complex permittivity is called loss tangent, $\tan \delta$ (see Equation 2), and it represents the efficiency of the material to convert absorbed energy into heat (the angle $\delta$ is the phase difference between the polarization of the material and the oscillating electric field).

$$
\tan \delta=\frac{\varepsilon^{\prime \prime}}{\varepsilon^{\prime}}
$$

The average power dissipated into the material per unit volume can be represented by the following simplified Equation 3 [43,44]:

$$
P_{d}(x, y, z)=\omega \varepsilon_{0} \varepsilon^{\prime \prime}{ }_{e f f} E^{2}{ }_{r m s}
$$

where $\mathrm{P}_{\mathrm{d}}$ is the power density in the material at the position $(x, y, z)$ expressed in $\mathrm{W} / \mathrm{m}^{3}, \omega=2 \pi \mathrm{f}$ (expressed in $\mathrm{Hz}$ ) with $\mathrm{f}$ being the frequency of the incident microwaves and $E_{\mathrm{rms}}$ the root mean square of the electric field strength at the position $(x, y, z)$, expressed in $\mathrm{V} / \mathrm{m}$.

The relative effective loss factor $\varepsilon^{\prime \prime}$ eff accounts for the polarization losses (dipolar, ionic, electronic and interfacial) combined with the conductivity losses. 
At the microwave frequencies, the two predominant loss mechanisms are the dipolar and the ionic ones. It is therefore obvious to what extent the reaction conditions typical of both hydrothermal synthesis and solution combustion synthesis represent the ideal environment for using microwaves as a heating source. Indeed, hydrothermal reaction conditions usually require the presence of inorganic salts (nitrates, chlorides, etc.) or other metallic precursors dissolved (or even sometimes suspended) in water combined with a mineralizing agent and an optional surfactant. Solution combustion synthesis conditions, on the other hand, rely on the presence of inorganic nitrate salts and an opportune organic fuel dissolved in water. Thus, in addition to the well-known strong microwave-absorbing ability of water, the addition of ionic species characterizing both these synthetic strategies will lead to higher microwave absorption due to ionic conductivity contributions. A representative example is the increase in the loss tangent of distilled water (at $25{ }^{\circ} \mathrm{C}$ and $2.45 \mathrm{GHz}$ ) from ca. 0.15 to approximately 1.6 with the addition of $0.5 \mathrm{~mol} / \mathrm{L}$ of sodium chloride (at the same temperature and frequency) [43].

Despite these remarkable characteristics, additional microwave-heating features form the basis of the advantages manifested in the synthesis of several inorganic materials, and they will be discussed separately in the following sub-sections. However, for a more exhaustive discussion of all the parameters/equations defined in this review manuscript, the readers are kindly requested to refer to the literature papers [42-44].

\subsection{Volumetric and Selective Nature of MW Heating}

On the basis of their interaction with electromagnetic radiation, materials can be classified as reflective, transparent or absorbing ones. In MW-absorbing materials, the microwave power penetration depth $\left(D_{\mathrm{p}}\right)$ needs to be evaluated, and for dielectric materials it can be described with the following simplified Equation 4, where $\lambda_{0}$ is the free space wavelength of the incident microwaves.

$$
D_{p}=\frac{\lambda_{0} \sqrt{\varepsilon^{\prime}{ }_{r}}}{2 \pi \varepsilon^{\prime \prime}{ }_{r}}
$$

$D_{\mathrm{p}}$ represents the depth from the outer surface of the material at which the value of $\mathrm{P}_{\mathrm{d}}$ has decreased to $1 / \mathrm{e}$ (i.e., $\sim 37 \%$ ) of its surface value. For several materials and reaction media the value of $D_{\mathrm{p}}$ is significantly higher with respect to the thickness of sample generally used (at least at a laboratory scale), thus the MW power dissipated (and the subsequent heat generation) is reasonably uniform throughout the whole material. This property of microwaves, known as volumetric heating, leads to the inversion of the classical temperature profile and to a significant reduction of the temperature gradient inside the reaction mixture. The latter situation is shown in Figure 1, where a comparison between the temperature profiles in a reaction mixture undergoing both conventional hydrothermal and microwave hydrothermal treatments is depicted. 
Figure 1. Example of temperature profiles occurring in a reaction mixture exposed to conventional heating (left, e.g., inside a stainless steel autoclave) and to microwave heating (right, e.g., inside a microwave transparent polytetrafluoroethylene (PTFE) reaction vessel).
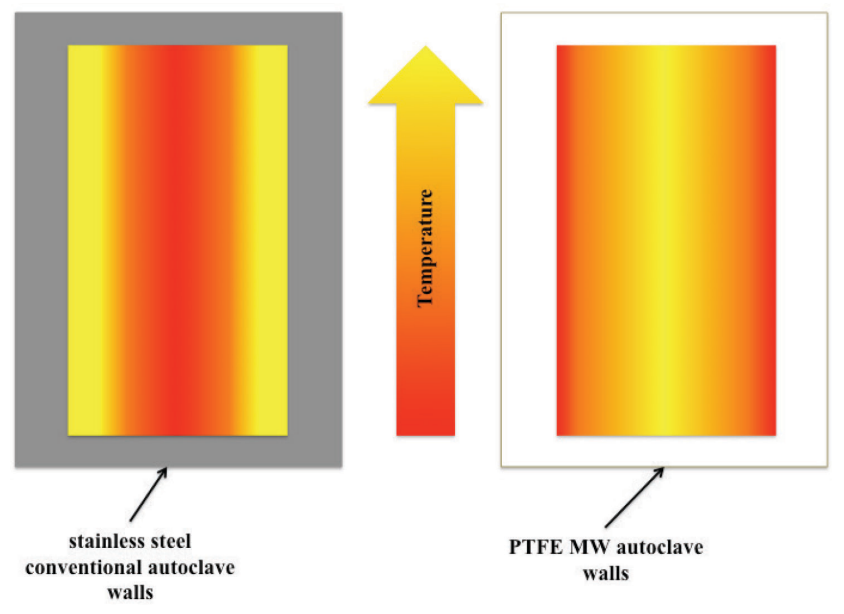

\subsection{Energy Efficiency Issues}

Direct and selective interaction of microwave energy with the reaction mixture, which favors the fast heating of the mixture in solution rather than the reactor's walls or other components, surely represents an intrinsic energy efficiency feature. It is clear that the possibility to transfer energy exactly where needed contributes to increasingly apply microwave-based technologies in a green process intensification perspective, as frequently reported in the literature during recent years [45,46]. Indeed, the obvious enhancement of reaction rates, manifested by most of the inorganic syntheses performed under microwave assistance (as will be detailed in the following section), is probably the main feature which is usually fundamental in defining microwave routes as more energy-efficient.

However, very recently the energy efficiency of microwave-assisted organic synthetic protocols has been critically assessed [47]. Mainly due to the lower electrical energy conversion capability of standard $2.45 \mathrm{GHz}$ magnetrons installed on commercial scientific equipments [48], it has been recommended to perform energy efficiency evaluations on a case by case basis, since the situation has been noted to be significantly different when moving from laboratory-scale single-mode reactors to larger batch reactors like multi-mode ones (for a detailed essay on the different microwave heating cavities and their components, the readers are kindly suggested to refer to [49]).

Concerning the specific field of inorganic synthesis, the same considerations are also valid. However, several strategies exist and are still under systematic investigation, in order to, at least, partially overcome these limitations. In particular, dedicated applicators equipped with proper impedance matching devices can significantly reduce the reflected power and power dissipated in regions different from the desired one. Moreover, the actual tendency of the market to develop new microwave generators, also able to perform a continuous impedance matching by tuning over a particular frequency range, will surely lead to more and more efficient syntheses [50].

The problems encountered with larger batch reactors are related to the penetration depth $\left(D_{\mathrm{p}}\right.$, see Equation 4). Indeed, with the increase of the batch scale, $D_{\mathrm{p}}$ could be extremely small leading to an almost heat-unaffected mixture. Understanding the importance of internal agitation in 
microwave-assisted chemistry [51], the latter circumstance will surely result in more pronounced temperature gradients. A further intriguing and practically un-explored possibility could be the use of microwave frequencies different from that most commonly used worldwide, i.e., $2.45 \mathrm{GHz}$. Particularly, the use of lower frequencies for a given material or solution will increase its $D_{p}$, as is clearly evident from Equation 4. Moreover, continuous flow syntheses are another interesting solution to the limitations of the reduced microwave penetration depth (when treating large batch reactors) [52-55] during the scaling up of microwave-hydrothermal technology. In this latter perspective, the use of multiple MW sources represents a further option.

On the other hand, from Section 4 it will become clear how solution combustion synthesis is not affected by all of these issues, since its energy efficiency is guaranteed by the fact that most of the required energy will be provided by harnessing the exothermic characteristics of the reaction itself.

\section{Microwave-Assisted Hydrothermal Synthesis of Engineered Nanomaterials}

Among the various wet chemical methods, the hydrothermal approach is the most promising method for the fabrication of nanostructured and microstructured materials in an acceptable crystalline phase as can be seen in Figure 2.

Figure 2. Transmission electron microscopy (TEM) image of $\mathrm{ZrO}_{2}$ nanopowders doped with $1 \%$ Pr obtained via microwave (MW)-assisted hydrothermal synthesis performed at $8 \mathrm{MPa}$ for $30 \mathrm{~min}$, according to the chemical procedure indicated in [56].

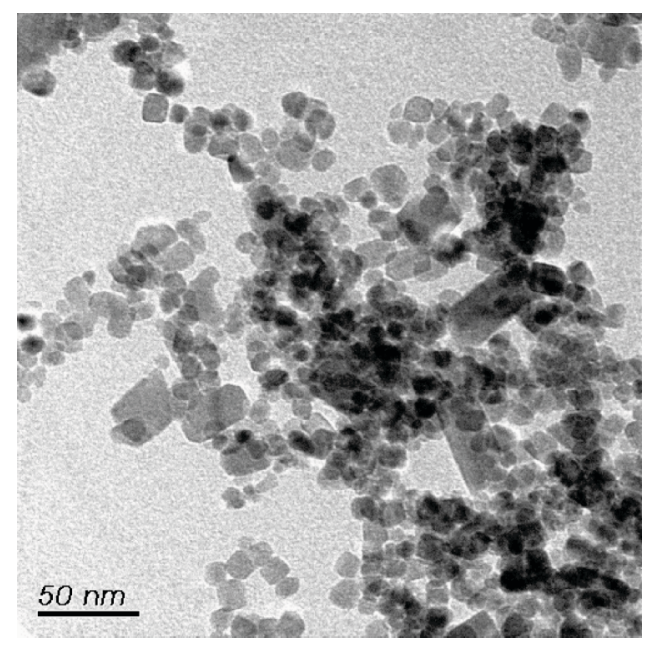

Indeed the ability to precipitate already crystallized powders directly from solution allows controlling the rate and uniformity of nucleation. This results in improved control of size and morphology of crystallites and in significantly reduced aggregation levels [57]. Moreover, crystallization phenomena constitute a self-purifying process, during which the growing crystals/crystallites tend to reject impurities present in the growth environment. The impurities are subsequently removed from the system together with the crystallizing solution, contrary to other synthesis routes, such as high temperature calcination. Thus, with the hydrothermal approach it is possible to synthesize powders in a one-step process, without the contamination typical of a reaction 
carried out in a closed system. Some key factors such as the reagent concentration, the reaction temperature and the reaction time are crucial for the morphology and crystallite size of the products.

From the pioneering work by Komarneni et al. [58], the main advantages of the MW-assisted hydrothermal route over conventional hydrothermal treatments are short reaction time, energy saving, good particle dispersion, high phase purity, high homogeneity in stoichiometry, and small particle size $[59,60]$. Most of the aforementioned advantages can be easily attributed to the significant reduction of the initial heating period (up to the set temperature), which characterizes dielectric heating over more conventional heat transfer mechanisms, as schematically reported in Figure 3.

Figure 3. Temperature profiles typical of microwave-assisted and conventionally-heated hydrothermal synthesis.

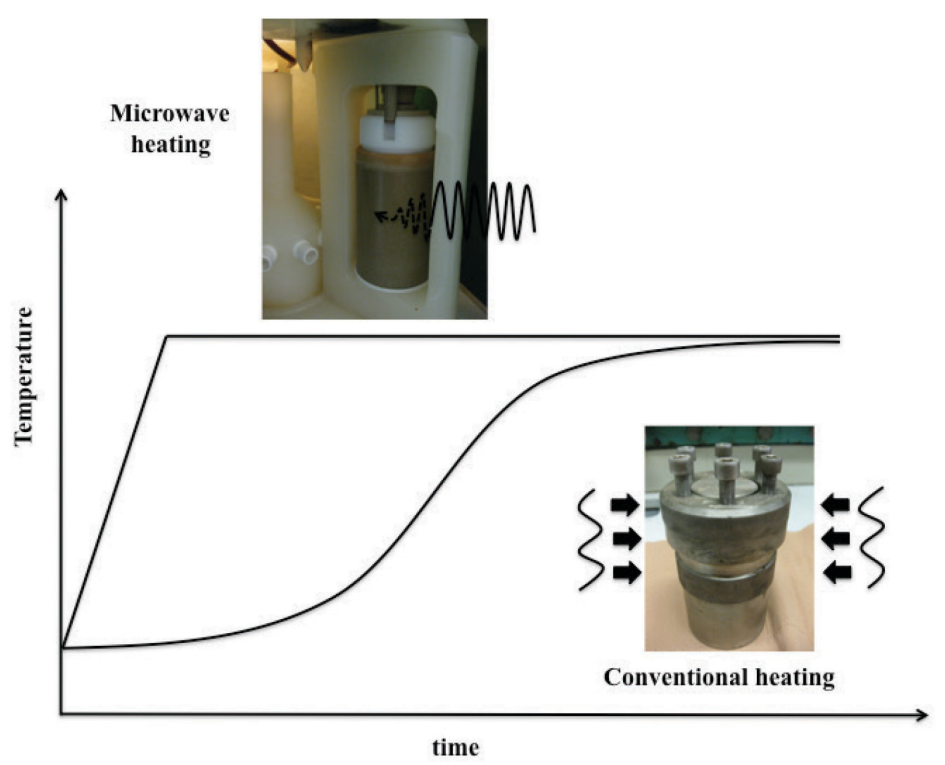

Indeed, the initial part of the heating period characterizing conventional hydrothermal syntheses can last many minutes; thus, it may result in non-uniform temperature profiles inside the autoclave (please refer to Figure 1).

By contrast, the gradient-less volumetric microwaves-based heating (right side of Figure 1) is able to provide the reaction mixture with a significantly uniform distribution of energy, which results in narrower particle size distributions [61-63].

During recent decades, hydrothermal synthetic techniques have been employed for the preparation of a wide variety of advanced engineered nanomaterials, a summary of which is reported in Table 1. Surely, the mostly studied and synthesized compounds are transition metal oxides and multi metal oxide materials $[20,59,64,65]$, although several examples can be found in scientific literature relating to the production of metal sulfides [59,64-68], hydroxyapatite [59,69] and different kinds of carbon-based nanostructures [59,70,71].

Recently, scientific attention has been focused on multiferroic compounds that exhibit the existence of simultaneous ferroelectric and ferromagnetic properties in a certain temperature range, since they have promising applications in spintronics, electromagnetic interference filters, magnetic recording media, sensors, and photovoltaic devices [72-76]. 
Among the multiferroic compounds, bismuth ferrite $\mathrm{BiFeO}_{3}(\mathrm{BFO})$ has received considerable attention in the past few years because of its characteristics, and a multitude of research work dealing with its conventional hydrothermal synthesis can be found in the scientific literature [77-79]. Most of these studies were devoted to investigating the role of several experimental processing parameters in the synthesis of a pure BFO phase, and reaction times ranging from 6-9 hours were always necessary for that purpose.

Table 1. Some of the different classes of materials synthesized by the hydrothermal technique.

\begin{tabular}{|c|c|c|c|}
\hline Class of materials & Main examples & $\begin{array}{c}\text { Some crystal shapes } \\
\text { observed }\end{array}$ & Ref. \\
\hline Transition metal oxides & $\begin{array}{l}\mathrm{TiO}_{2}, \mathrm{ZnO}, \mathrm{ZrO}_{2} \\
\mathrm{Fe}_{2} \mathrm{O}_{3}, \mathrm{Fe}_{3} \mathrm{O}_{4}\end{array}$ & $\begin{array}{l}\text { Nanoparticles, nanotubes, } \\
\text { nanowires, nanorods, } \\
\text { nanocubes, nanoribbons }\end{array}$ & {$[20,59,64,65]$} \\
\hline Multimetal oxides & $\begin{array}{c}\mathrm{BaTiO}_{3} \\
\mathrm{La}_{1-x} \mathrm{Sr}_{x} \mathrm{MnO}_{3}, \mathrm{BiFeO}_{3}\end{array}$ & $\begin{array}{l}\text { Nanoparticles, polyhedrons, } \\
\text { nanoplatelets, nanocubes }\end{array}$ & {$[20,64,65]$} \\
\hline Metal sulfides & $\mathrm{CdS}, \mathrm{ZnS}, \mathrm{CuS}, \mathrm{SnS}$ & Nanoparticles, nanotubes, & {$[59,64-68]$} \\
\hline Biomaterials & Hydroxyapatite & $\begin{array}{c}\text { Needle-like (frequently), } \\
\text { nanospheres, nanorods, } \\
\text { nanowires, whiskers, } \\
\text { platelets }\end{array}$ & {$[59,69]$} \\
\hline $\begin{array}{c}\text { Carbon-based } \\
\text { nanostructured materials }\end{array}$ & \multicolumn{2}{|c|}{$\begin{array}{l}\text { Carbon nanotubes, nanospheres, nanofibers, } \\
\text { graphene-based materials }\end{array}$} & {$[59,70,71]$} \\
\hline
\end{tabular}

On the other hand, in the early nineties Komarneni et al. [80] proposed the microwave hydrothermal synthesis of BFO to obtain highly crystalline agglomerated particles in one heating step. This study demonstrated that the microwave-hydrothermal approach was very efficient in terms of kinetics for the synthesis and processing of both binary and ternary ceramic oxide powders. More recently [81], a comparison of three different methods for preparing BFO polycrystals has been reported: (i) the classic hydrothermal synthesis, (ii) the microwave heating in the solid state and (iii) the microwave-assisted hydrothermal method. The best material in terms of purity and enhanced reproducibility was obtained with the third method, which was also described as the most environmental-friendly, since it employed moderate temperatures $\left(T=200{ }^{\circ} \mathrm{C}\right)$ and significantly less time $(30 \mathrm{~min})$. In the last few years, several experimental studies concerning the microwave-hydrothermal approach have been undertaken in order to obtain single-phase crystalline bismuth ferrite nanocrystals with a high degree of homogeneity and uniformity in particle size at even faster reaction rates and low temperatures.

In a recent study by our group, an easy microwave hydrothermal synthesis route was optimized for the preparation of $\mathrm{BiFeO}_{3}$ pure-phase [82]. In particular, the work focused on the influence of process parameters (i.e., precursor ratio, mineralizer concentration, temperature, time and the use of inorganic chelating agents) on phase formation, particle size distribution and morphology. Single phase BFO was obtained at $180{ }^{\circ} \mathrm{C}$ using a concentration of $10 \mathrm{M} \mathrm{KOH}$ mineralizer (Figure 4) or at $200{ }^{\circ} \mathrm{C}$ using $8 \mathrm{M}$ $\mathrm{KOH}$, in a $30 \mathrm{~min}$ total reaction time in both cases. Moreover, the presence of $\mathrm{Na}_{2} \mathrm{CO}_{3}$ acting as an electron donor allowed the reaction to be performed at lower $\mathrm{KOH}$ concentrations and temperatures. The 
particle morphology evolution followed the sequence: spherical, lamellar, lamellar semi-cubic, and cubic. Whereas with $\mathrm{Na}_{2} \mathrm{CO}_{3}$ addition the evolution was as follows: lamellar semi-cubic, cubic, and prismatic truncated octahedron shape. The main differences of this latter microwave-assisted hydrothermal approach [82] with respect to those mentioned above [80,81] (constituting two of the most significant ones employing $\mathrm{MW}$ heating) for the preparation of $\mathrm{BiFeO}_{3}$ nanoparticles and nanostructured particles are summarized in Table 2.

In all of the experiments carried out in [82], microwave heating allowed obtaining a perfect control over the heating rate and reducing the ramp to the reaction temperature to only $5 \mathrm{~min}$ (in comparison to the 15 min needed in the example in [81]). This precise and immediate transfer of energy, again, must be emphasized as the key step manifested in the majority of microwave-assisted synthetic inorganic protocols, leading to the observed advantages. Moreover, the temperature adopted in [82] was reduced by approximately $20{ }^{\circ} \mathrm{C}$ with respect to the majority of syntheses reported, including those exploiting microwave heating.

Figure 4. Scanning electron microscopy (SEM) images and X-ray diffractometry (XRD) pattern of pure bismuth ferrite $\left(\mathrm{BiFeO}_{3}\right)$ phase synthesized according to the microwave-assisted hydrothermal procedure optimized in [74], i.e., at $180{ }^{\circ} \mathrm{C}$ for $30 \mathrm{~min}$ with a $\mathrm{KOH}$ concentration of $10 \mathrm{~mol} / \mathrm{L}$.
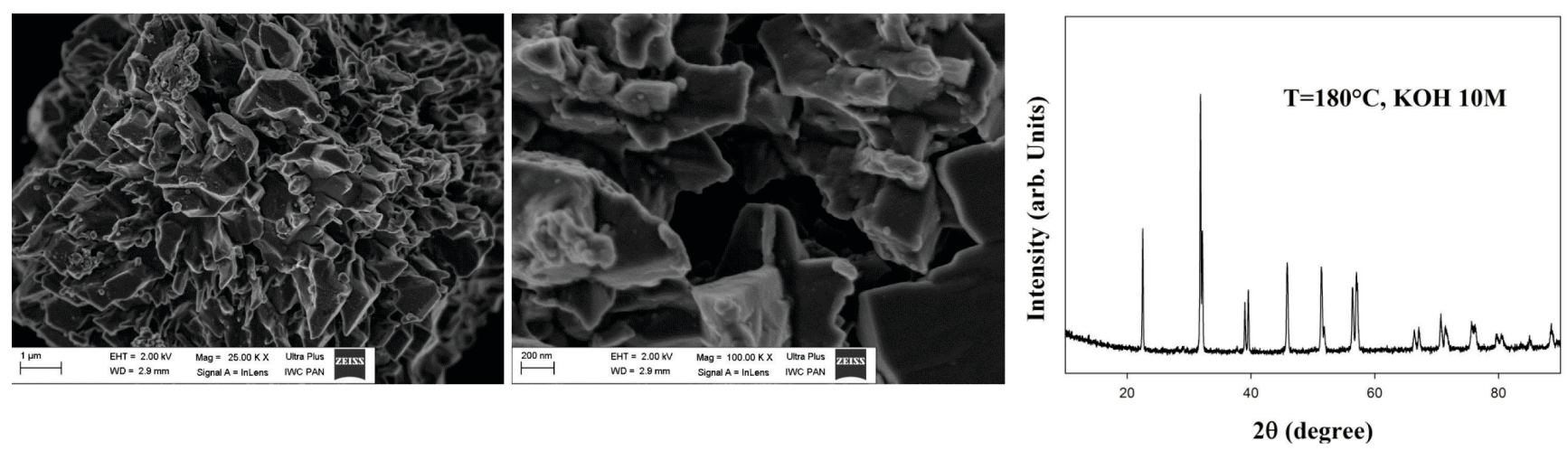

Table 2. Comparison of three different microwave-assisted hydrothermal synthesis strategies proposed for the obtainment of single $\mathrm{BiFeO}_{3}$ phase.

\begin{tabular}{cccc}
\hline Temperature $\left({ }^{\circ} \mathbf{C}\right)$ & Time (min) & Product & Ref. \\
\hline ca. 194 & 120 & $\begin{array}{c}\text { agglomerated } \\
\text { rombohedral } \\
\text { BiFeO }_{3} \text { particles }\end{array}$ & {$[80]$} \\
200 & 30 & $\begin{array}{c}\text { polyhedral } \mathrm{BiFeO}_{3} \\
\text { nano-structured } \\
\text { particles }\end{array}$ & {$[81]$} \\
\hline 180 & 30 & $\begin{array}{c}\text { nanocubic } \mathrm{BiFeO}_{3} \\
\text { aggregates }\end{array}$ & {$[82]$} \\
\hline
\end{tabular}




\section{Microwave Energy Transfer in the Ignition of Solution Combustion Synthesis}

Combustion synthesis (CS) is a relatively new inorganic material manufacturing procedure, originating from the discovery of solid flame phenomena by Merzhanov and co-workers [83,84]. Very quickly it became the most promising method for the synthesis of high temperature ceramics, intermetallics and different kinds of composite materials. The main reason can be found in its intrinsic energy saving characteristics, since most of the energy needed for the synthesis is released by the reaction itself. Indeed, CS exploits exothermic reactions occurring among the reactants; after a proper ignition (i.e., the reaction mixture is heated up to the so-called ignition temperature), the reactants start reacting in a self-sustaining manner, thus requiring no further energy from an external source, since the harnessing of the heat produced by the reaction itself allows completion of the reaction in the whole reactive volume [85]. Typically, two different ignition strategies are distinguishable, leading to the self-propagating high-temperature synthesis (SHS) and to the thermal explosion (TE) modes of combustion synthesis. In the SHS type, the exothermic reaction is ignited at one end of the reactive volume so that the reaction self-propagates to the opposite side of the sample, while in the TE method of combustion the entire reactive volume is heated up homogeneously and uniformly until the reaction takes place almost simultaneously in the entire specimen [85].

Although initially the performance of CS was limited among mixtures of powders, or could benefit from the optional use of a gaseous phase [86], nowadays CS has reached a significant level of versatility and diversity [87]. Particularly, combustion synthesis performed in aqueous solution is a relatively new method for preparation of oxide-based engineered nanomaterials [88]. In summary, solution combustion synthesis exploits exothermic self-sustaining reactions occurring between metal nitrates and different kinds of organic fuels (e.g., glycine, urea, citric acid, polyethylene glycol, etc.) in homogeneous solutions. The main steps involved in this synthesis strategy are schematically summarized in Figure 5. Also, in this case the ignition can occur locally (leading to a layer by layer propagation) or volumetrically (leading to a nearly instantaneous reaction).

Most of the more conventional soft-chemistry routes, including the above-discussed hydrothermal synthesis, even if performed by microwave-assistance, are significantly more energy and time consuming.

Moreover - although to a significantly lesser extent with respect to hydrothermal syntheses — with the ever-deepening research findings in the field of CS, a satisfactory control over the crystallite size has been achieved by opportunely modifying the ratio between the metal nitrate and the fuel, or by changing the fuel itself as well as the metal precursor anion $[88,89]$.

Being able to change the particle size distribution by simply changing the ignition strategy from a conventional hot plate to the direct interaction of almost the whole reaction mixture with microwave energy gives more desirable results. Indeed, this latter opportunity has been observed in several works [90-92] accompanied by the typical shorter reaction times, which, as in this case, are all direct consequences of the volumetric nature of microwave heating. Moreover, the fact that microwave ignition of solution combustion synthesis at the laboratory scale is more prone to occur volumetrically (i.e., referred to as Thermal Explosion in traditional solid state performed CS reactions) further assures a more uniform thermal history to the reactive solution. Moreover, the possibility that microwaves continue to furnish energy to the reaction (despite the adverse temperature gradient), even after 
ignition and/or completion, must be mentioned. This happens based on the dielectric properties of the forming solid products and leads to the possibility of modifying the cooling rates as well.

Figure 5. Schematic representation of the main steps characterizing the solution combustion synthesis approach to produce oxide-based engineered nanomaterials.

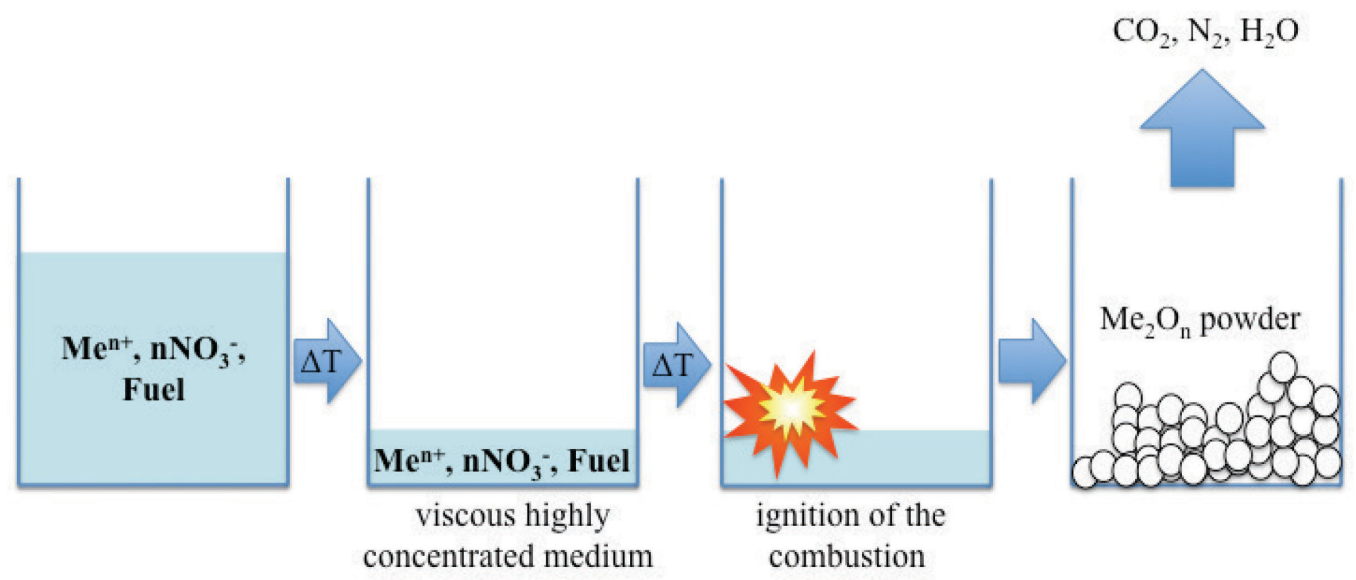

Table 3. Summary of some of the latest modifications of combustion synthesis for the preparation of engineered nanomaterials.

\begin{tabular}{|c|c|c|c|c|}
\hline $\begin{array}{l}\text { Synthetic } \\
\text { approach }\end{array}$ & $\begin{array}{c}\text { Distinctive } \\
\text { characteristics }\end{array}$ & $\begin{array}{c}\text { Main } \\
\text { classes of } \\
\text { materials } \\
\text { obtainable }\end{array}$ & $\begin{array}{l}\text { Examples of } \\
\text { synthesized } \\
\text { compounds }\end{array}$ & Ref. \\
\hline $\begin{array}{l}\text { Solution } \\
\text { combustion } \\
\text { synthesis }\end{array}$ & $\begin{array}{l}\text { The solution of the } \\
\text { metal precursor(s) } \\
\text { nitrate(s) and the } \\
\text { fuel is slowly } \\
\text { evaporated and then } \\
\text { ignited locally or } \\
\text { volumetrically. The } \\
\text { exothermic reaction } \\
\text { occurs between fuel } \\
\text { and oxygen- } \\
\text { containing species } \\
\text { derived from the } \\
\text { decomposition of } \\
\text { nitrates }\end{array}$ & $\begin{array}{c}\text { - Binary and } \\
\text { more } \\
\text { complex } \\
\text { metal oxide } \\
\text { nanopowders } \\
\text { - metal } \\
\text { nanopowders }\end{array}$ & $\begin{array}{c}-\mathrm{TiO}_{2}, \mathrm{ZnO}, \\
\mathrm{LaFeO}_{3}, \mathrm{BiFeO}_{3} \\
\text { - Ni, } \mathrm{Cu} \text { and their } \\
\text { alloys }\end{array}$ & {$[88,91-93,94]$} \\
\hline
\end{tabular}


Table 3. Cont.

\begin{tabular}{|c|c|c|c|c|}
\hline $\begin{array}{l}\text { Impregnated } \\
\text { layer and } \\
\text { combustion }\end{array}$ & $\begin{array}{l}\text { The reactive } \\
\text { solution is } \\
\text { impregnated with } \\
\text { an inert porous } \\
\text { oxide support or } \\
\text { with a reactive } \\
\text { cellulose paper also } \\
\text { acting as a fuel. } \\
\text { - a productivity of } \\
0.5-2 \mathrm{~kg} / \mathrm{h} \text { of } \\
\text { nanoparticles has } \\
\text { been reached by a } \\
\text { continuous } \\
\text { synthesis approach }\end{array}$ & $\begin{array}{l}\text { - binary and } \\
\text { more } \\
\text { complex } \\
\text { oxides }\end{array}$ & $\begin{array}{c}\mathrm{ZnO}, \mathrm{MgO}, \mathrm{Ce}_{1-} \\
{ }_{x} \mathrm{Pt}_{\mathrm{x}} \mathrm{O}_{2}, \\
\mathrm{CuO} / \mathrm{ZnO} / \mathrm{ZrO}_{2} / \mathrm{Pd} \\
\text { based catalysts }\end{array}$ & {$[95,96]$} \\
\hline $\begin{array}{l}\text { Carbon } \\
\text { combustion } \\
\text { synthesis }\end{array}$ & $\begin{array}{l}\text { The exothermic } \\
\text { oxidation reaction } \\
\text { of carbon to carbon } \\
\text { dioxide generates a } \\
\text { reaction wave that } \\
\text { propagates through } \\
\text { the solid reactant } \\
\text { mixture. The } \\
\text { product of the } \\
\text { exothermic reaction } \\
\text { is not incorporated } \\
\text { into the final } \\
\text { product, leading to } \\
\text { several advantages } \\
\text { (e.g., smaller } \\
\text { particles). }\end{array}$ & $\begin{array}{c}\text { - Perovskite } \\
\text { oxides }\end{array}$ & $\begin{array}{c}\mathrm{BaTiO}_{3}, \mathrm{SrTiO}_{3} \\
\mathrm{LiNbO}_{3}, \mathrm{CoFe}_{2} \mathrm{O}_{4}\end{array}$ & {$[97,98]$} \\
\hline
\end{tabular}

Solution combustion synthesis has recently shown several new trends, which deserve particular attention. Particularly, it has been noted that the nature of the fuel-oxidizer system and its ratio can also cause a radical change in the expected product, leading to the usually expected and desired oxide or eventually to metallic nanoparticles, and thereby suggesting a new synthetic methodology for metal and metallic alloy-based nanomaterials [93]. Moreover, a different combustion synthesis approach, named Carbon Combustion Synthesis, which does not occur properly in solution and which exploits the high exothermicity of the carbon oxidation to $\mathrm{CO}_{2}$, was recently developed to obtain nanostructured materials [97,98], accompanied by a continuous large-scale nanomaterial preparation procedure based on the principles of solution CS (the so-called impregnated layer and combustion) [95,99]. All of these latter novel approaches are summarized in Table 3 where they are compared to solution combustion synthesis itself in terms of their distinctive characteristics and materials obtainable/obtained. In all likelihood, coupling of these latter novelties with a significantly more energy efficient ignition strategy, like microwaves, is simply a matter of time. 


\section{Concluding Remarks}

This manuscript does not intend to exhaustively cover all the possible applications of microwave energy in the hydrothermal as well as in the solution combustion synthesis of engineered nanomaterials; nevertheless, it does aim to present a wide and descriptive approach of the peculiar characteristics of well conceived modern syntheses using microwave energy as a heating source.

The most recent trends in microwave irradiation of chemical environments are directed toward the utilization of combined techniques [45]. For this reason, we have presented results for microwave-assisted hydrothermal and microwave-assisted solution combustion syntheses. The emerging interest in the production of selected engineered nanosized oxide-based materials pushed us toward this class of inorganic compounds.

Both hydrothermal and solution combustion synthesis approaches significantly benefit from the ability of microwaves to directly generate the necessary heat (for the reaction completion or simply ignition) inside the reactant mixture.

A success story of a well-crystallized single phase complex oxide compound has been described: the microwave-assisted hydrothermal synthesis of perovskite $\mathrm{BiFeO}_{3}$ oxide was performed in significantly shorter reaction times with respect to conventional hydrothermal procedures and with a narrower particles' size distribution.

Similar advantages have also been noted when comparing conventional heating and microwave heating for the ignition of solution combustion synthesis.

In all cases, the ability of microwaves to directly furnish the entire reaction medium with a more uniform energy distribution, with a resulting almost gradient-less temperature profile, has been considered to be the crucial feature marking the originality of these syntheses.

Despite the reported advantages and intrinsic characteristics, the limitations of a microwave energy source have not been ignored in this review paper.

Moreover, considerations of the possible application of dielectric heating to novel aspects of both hydrothermal and solution combustion synthesis approaches or simply considerations of the scaling up of microwave technology have been made.

\section{Acknowledgments}

The authors are particularly grateful to Paolo Veronesi, University of Modena and Reggio Emilia for helping with experimental set-up, cavity geometry and electromagnetic field simulations and to Antonino Rizzuti, Polytechnic University of Bari, Italy, for part of the syntheses and characterization work. They express their thanks to Adam Presz for some SEM images, to Statutory Funds of IHHP and to Witold Lojkowski from Institute of High Pressure Physics, Polish Academy of Science, Warsaw, Poland.

The financial support from Project PRIN 2009 "Microwave applicators design: from numerical simulation to materials selection"-Prot. 2009WXXLY2_001 funded by MIUR-Italy was particularly appreciated. 


\section{Conflicts of Interest}

The authors declare no conflict of interest.

\section{References}

1. Rao, K.J.; Vaidhyanathan, B.; Ganguli, M.; Ramakrishnan, P.A. Synthesis of inorganic solids using microwaves. Chem. Mater. 1999, 11, 882-895.

2. Jansen, M. A concept for synthesis planning in solid-state chemistry. Angew. Chem. Int. Ed. 2002, 41, 3746-3766.

3. Ramesh, P.D.; Vaidhyanathan, B.; Ganguli, M.; Rao, K.J. Synthesis of $\beta$-SiC powder by use of microwave radiation. J. Mater. Res. 1994, 9, 3025-3027.

4. Ramesh, P.D.; Rao, K.J. Microwave assisted synthesis of aluminum nitride. Adv. Mater. 1995, 7, 177-179.

5. Rizzuti, A.; Leonelli, C. Crystallization of aragonite particles from solution under microwave irradiation. Powder Technol. 2008, 186, 255-262.

6. Mastrovito, C.; Lekse, J.W.; Aitken, J.A. Rapid solid-state synthesis of binary group 15 chacogenides using microwave irradiation. J. Solid State Chem. 2007, 180, 3262-3270.

7. Bhunia, S.; Bose, D.N. Microwave synthesis, single crystal growth and characterization of ZnTe. J. Crystal Growth 1998, 186, 535-542.

8. Vaidhyanathan, B.; Rao, K.J. Microwave assisted synthesis of technologically important transition metal silicides. J. Mater. Res. 1997, 12, 3225-3229.

9. Vaidhyanathan, B.; Raizada, P.; Rao, K.J. Microwave assisted fast solid state synthesis of niobates and titanates. J. Mater. Sci. Lett. 1997, 16, 2022-2025.

10. Wang, Y.; Herron, N. Nanometer-sized semiconductor clusters: materials synthesis, quantum size effects, and photophysical properties. J. Phys. Chem. 1991, 95, 525-532.

11. Berry, C.R. Structure and optical absorption of AgI microcrystals. Phys. Rev. 1967, 161, 848-851.

12. Hischier, R.; Walser, T. Life cycle assessment of engineered nanomaterials: state of the art and strategies to overcome existing gaps. Sci. Total Environ. 2012, 425, 271-282.

13. Gopalakrishnan, J. Chimie douce approaches to the synthesis of metastable oxide materials. Chem. Mater. 1995, 7, 1265-1275.

14. Hubert-Pfalzgraf, L.G. To what extent can design of molecular precursors control the preparation of high tech oxides? J. Mater. Chem. 2004, 14, 3113-3123.

15. Roy, R. Ceramics by the solution-sol-gel route. Science 1987, 238, 1664-1669.

16. Vioux, A. Nonhydrolytic sol-gel routes to oxides. Chem. Mater. 1997, 9, 2292-2299.

17. Niederberger, M.; Garnweitner, G. Organic reaction pathways in the nonaqueous synthesis of metal oxide nanoparticles. Chem. Eur. J. 2006, 12, 7282-7302.

18. Giordano, C.; Antonietti, M. Synthesis of crystalline metal nitride and metal carbide nanostructures by sol-gel chemistry. Nano Today 2011, 6, 366-380.

19. Valizadeh, A.; Mikaeili, H.; Samiei, M.; Farkhani, S.M.; Zarghami, N.; Kouhi, M.; Akbarzadeh, A.; Davaran, S. Quantum dots: Synthesis, bioapplications, and toxicity. Nanoscale Res. Lett. 2012, 7, 480 . 
20. Patzke, G.R.; Zhou, Y.; Kontic, R.; Conrad, F. Oxide nanomaterials: Synthetic developments, mechanistic studies, and technological innovations. Angew. Chem. Int. Ed. 2011, 50, 826-859.

21. Dias, A.; Ciminelli, V.S.T. Electroceramic materials of tailored phase and morphology by hydrothermal technology. Chem. Mater. 2003, 15, 1344-1352.

22. Hayashi, H.; Hakuta, Y. Hydrothermal synthesis of metal oxide nanoparticles in supercritical water. Materials 2010, 3, 3794-3817.

23. Demazeau, G. Solvothermal reactions: An original route for the synthesis of novel materials. $J$. Mater. Sci. 2008, 43, 2104-2114.

24. Namratha, K.; Byrappa, K. Novel solution routes of synthesis of metal oxide and hybrid metal oxide nanocrystals. Progr. Crystal Growth Charact. Mater. 2012, 58, 14-42.

25. Kingsley, J.J.; Patil, K.C. A novel combustion process for the synthesis of fine particle alpha-alumina and related oxide materials. Mater. Lett. 1988, 6, 427-432.

26. Manoharan, S.S.; Patil, K.C. Combustion route to fine particle perovskite oxides. J. Solid State Chem. 1993, 102, 267-276.

27. Patil, K.C.; Aruna, S.T.; Ekambaram, S. Combustion synthesis. Curr. Opin. Solid State Mater. Sci. 1997, 2, 158-165.

28. Patil, K.C.; Aruna, S.T.; Mimani, T. Combustion synthesis: an update. Curr. Opin. Solid State Mater. Sci. 2002, 6, 507-512.

29. Mukasyan, A.S.; Epstein, P.; Dinka, P. Solution combustion synthesis of nanomaterials. Proc. Comb. Inst. 2007, 31, 1789-1795.

30. Aruna, S.T.; Mukasyan, A.S. Combustion synthesis and nanomaterials. Curr. Opin. Solid State Mater. Sci. 2008, 12, 44-50.

31. Ruiz-Gomez, M.A.; Gomez-Solis, C.; Zarazua-Morin, M.E.; Torres-Martinez, L.M.; Juarez-Ramirez, I.; Sanchez-Martinez, D.; Figueroa-Torres, M.Z. Innovative solvo-combustion route for the rapid synthesis of $\mathrm{MoO}_{3}$ and $\mathrm{Sm}_{2} \mathrm{O}_{3}$ materials. Ceram. Int. 2014, 40, 1893-1899.

32. Gedye, R.; Smith, F.; Westaway, K.; Ali, H.; Baldisera, L.; Laberge, L.; Rousell, J. The use of microwave ovens for rapid organic synthesis. Tetrahedron Lett. 1986, 27, 279-282.

33. Giguere, R.J.; Bray, T.L.; Duncan, S.M.; Majetich, G. Application of commercial microwave ovens to organic synthesis. Tetrahedron Lett. 1986, 27, 4945-4948.

34. Adam, D. Microwave chemistry: out of the kitchen. Nature 2003, 421, 571-572.

35. Loupy, A. Microwaves in Organic Synthesis; Wiley-VCH: Weinheim, Germany, 2002.

36. Kappe, C.O. Controlled microwave heating in modern organic synthesis. Angew. Chem. Int. Ed. 2004, 43, 6250-6284.

37. Corradi, A.; Leonelli, C.; Rizzuti, A.; Rosa, R.; Veronesi, P.; Grandi, R.; Baldassari, S.; Villa, C. New "green" approaches to the synthesis of pyrazole derivatives. Molecules 2007, 12, 1482-1495.

38. Leonelli, C.; Lojkowski, W. Main development directions in the application of microwave irradiation to the synthesis of nanopowders. Chem. Today 2007, 25, 34-38.

39. Anastas, P.T.; Warner, J.C. Green Chemistry: Theory and Practice; Oxford University Press: New York, NY, USA, 1998.

40. Huang, J.; Xia, C.; Cao, L.; Zeng, X. Facile microwave hydrothermal synthesis of zinc oxide one-dimensional nanostructure with three-dimensional morphology. Mater. Sci. Eng. B 2008, 150, 187-193. 
41. Shi, W.; Song, S.; Zhang, H. Hydrothermal synthetic strategies of inorganic semiconducting nanostructures. Chem. Soc. Rev. 2013, 42, 5714-5743.

42. Metaxas, A.C. Foundations of Electroheat: A Unified Approach; John Wiley and Sons: Chichester, UK, 1996.

43. Gupta, M.; Eugene, W.W.L. Microwaves-Theory. In Microwaves and Metals; John Wiley and Sons: Singapore, 2007 and references therein.

44. Metaxas, A.C.; Meredith, R.J. Industrial Microwave Heating; Peter Peregrinus: London, UK, 1983.

45. Leonelli, C.; Mason, T.J. Microwave and ultrasonic processing: Now a realistic option for industry. Chem. Eng. Process. 2010, 49, 885-900.

46. Rosa, R.; Veronesi, P.; Leonelli, C. A review on combustion synthesis intensification by means of microwave energy. Chem. Eng. Process. 2013, 71, 2-18.

47. Moseley, J.D.; Kappe, C.O. A critical assessment of the greenness and energy efficiency of microwave-assisted organic synthesis. Green Chem. 2011, 13, 794-806.

48. Nüchter, M.; Müller, U.; Ondruschka, B.; Tied, A.; Lautenschläger, W. Microwave-assisted chemical reactions. Chem. Eng. Technol. 2003, 26, 1207-1216.

49. Chan, T.V.C.T.; Reader, H.C. Understanding Microwave Heating Cavities; Artech House: Norwood, UK, 2000.

50. For further details see for example: http://www.mksinst.com, www.sairem.com.

51. Ferrero, M.A.; Kremsner, J.M.; Kappe, C.O. Nonthermal microwave effects revisited: on the importance of internal temperature monitoring and agitation in microwave chemistry. J. Org. Chem. 2008, 73, 36-47.

52. Corradi, A.B.; Bondioli, F.; Ferrari, A.M.; Focher, B.; Leonelli, C. Synthesis of silica nanoparticles in a continuous-flow microwave reactor. Powder Technol. 2006, 167, 45-48.

53. Katsuki, H.; Furuta, S.; Komarneni, S. Semi-continuous and fast synthesis of nanophase cubic $\mathrm{BaTiO}_{3}$ using a single-mode home-built microwave reactor. Mater. Lett. 2012, 83, 8-10.

54. Wiles, C.; Watts, P. Continuous flow reactors: A perspective. Green Chem. 2012, 14, 38-54.

55. Nishioka, M.; Miyakawa, M.; Daino, Y.; Kataoka, H.; Koda, H.; Sato, K.; Suzuki, T.M. Single-mode microwave reactor used for continuous flow reactions under elevated pressure. Ind. Eng. Chem. Res. 2013, 52, 4683-4687.

56. Bondioli, F.; Ferrari, A.M.; Braccini, S.; Leonelli, C.; Pellacani, G.C.; Opalińska, A.; Chudoba, T.; Grzanka, E.; Palosz, B.; Lojkowski, W. Microwave-hydrothermal synthesis of nanocrystalline Pr-doped zirconia powders at pressures up to $8 \mathrm{MPa}$, Interfacial Effects and Novel Properties of Nanomaterials. Solid State Phenom. 2003, 94, 193-196.

57. Riman, R.E. High Performance Ceramics: Surface Chemistry in Processing Technology; Pugh, R., Bergstrom, L., Eds.; Marcel-Dekker: New York, NY, USA, 1993.

58. Komarneni, S.; Roy, R.; Li, H.Q. Microwave-hydrothermal synthesis of ceramic powders. Mater. Res. Bull. 1992, 27, 1393-1405.

59. Byrappa, K.; Adschiri, T. Hydrotermal technology for nanotechnology. Prog. Cryst. Growth Charact. Mater. 2007, 57, 117-166.

60. Yoshimura, M.; Byrappa, K. Hydrothermal processing of materials: past, present and future. $J$. Mater. Sci. 2008, 43, 2085-2103. 
61. Van Gerven, T.; Stankiewicz, A. Structure, energy, synergy, time-the fundamentals of process intensification. Ind. Eng. Chem. Res. 2009, 48, 2465-2474.

62. Schwalbe, T.; Autze, V.; Hohmann, M.; Stirner, W. Novel innovation systems for a cellular approach to continuous process chemistry from discovery to market. Org. Proc. Res. Devel. 2004, $8,440-454$.

63. Leonelli, C.; Rizzuti, A.; Rosa, R.; Corradi, A.B.; Veronesi, P. Numerical simulation of a microwave reactor used in synthesis of nanoparticles. In Proceedings of IMPI 44th Annual Symposium, Denver, CO, USA, 14-16 July 2010.

64. Baghbanzadeh, M.; Carbone, L.; Cozzoli, P.D.; Kappe, C.O. Microwave-assisted synthesis of colloidal inorganic nanocrystals. Angew. Chem. Int. Ed. 2011, 50, 11312-11359.

65. Yao, W.T.; Yu, S.H. Recent advances in hydrothermal syntheses of low dimensional nanoarchitectures. Int. J. Nanotechnol. 2007, 4, 129-162.

66. Yan, S.; Wang, B.; Shi, Y.; Yang, F.; Hu, D.; Xu, X.; Wu, J. Hydrothermal synthesis of CdS nanoparticle/functionalized graphene sheet nanocomposites for visible-light photocatalytic degradation of methyl orange. Appl. Surf. Sci. 2013, 285P, 840-845.

67. Wan, H.; Ji, X.; Jiang, J.; Yu, J.; Miao, L.; Zhang, L.; Bie, S.; Chen, H.; Ruan, Y. Hydrothermal synthesis of cobalt sulfide nanotubes: The size control and its application in supercapacitors. $J$. Power Sources 2013, 243, 396-402.

68. Yan, X.; Michael, E.; Komarneni, S.; Brownson, J.R.; Yan, Z.F. Microwave- and conventionalhydrothermal synthesis of CuS, SnS and ZnS: Optical properties. Ceram. Int. 2013, 39, 4757-4763.

69. Shojai, M.S.; Khorasani, M.T.; Khoshdargi, E.D.; Jamshidi, A. Synthesis methods for nanosized hydroxyapatite with diverse structures. Acta Biomat. 2013, 9, 7591-7621.

70. Hu, B.; Wang, K.; Wu, L.; Yu, S.H.; Antonietti, M.; Titirici, M.M. Engineering carbon materials from the hydrothermal carbonization process of biomass. Adv. Mater. 2010, 22, 813-828.

71. Chen, P.; Yang, J.J.; Li, S.S.; Wang, Z.; Xiao, T.Y.; Qian, Y.H.; Yu, S.H. Hydrothermal synthesis of macroscopic nitrogen-doped graphene hydrogels for ultrafast supercapacitors. Nano Energy 2013, 2, 249-256.

72. Eerenstein, W.; Mathur, N.D.; Scott, J.F. Multiferroic and magnetoelectric materials, Nature, 2006, 442, 759-765.

73. Wang, J.; Neaton, J.B.; Zheng, H.; Nagarajan, V.; Ogale, S.B.; Liu, B.; Viehland, D.; Vaidhyanathan, V.; Schlom, D.G.; Waghmare, U.V.; et al. Epitaxial $\mathrm{BiFeO}_{3}$ multiferroic thin film heterostructures. Science 2003, 299, 1719-1722.

74. Hur, N.; Park, S.; Sharma, P.A.; Ahn, J.S.; Guha, S.; Cheong, S.W. Electric polarization reversal and memory in a multiferroic material induced by magnetic fields. Nature 2004, 429, 392-395.

75. Seidel, J.; Martin, L.W.; He, Q.; Zhan, Q.; Chu, Y.H.; Rother, A.; Hawkridge, M.E.; Maksymovych, P.; Yu, P.; Gajek, M.; et al. Conduction at domain walls in oxide multiferroics. Nat. Mater. 2009, 8, 229-234.

76. Choi, T.; Lee, S.; Choi, Y.J.; Kiryukhin, V.; Cheong, S.W. Switchable ferroelectric diode and photovoltaic effect in $\mathrm{BiFeO}_{3}$. Science 2009, 324, 63-66.

77. Han, S.H.; Kim, K.S.; Kim, H.-G.; Lee, H.-G.; Kang, H.-W.; Kim, J.S.; Cheon, C.I. Synthesis and characterization of multiferroic $\mathrm{BiFeO}_{3}$ powders fabricated by hydrothermal methods. Ceram. Int . 2010, 36, 1365-1375. 
78. Wang, Y.; Xu, G.; Ren, Z.; Wei, X.; Weng, W.; Du, P.; Shen, G.; Han, G. Mineralizer-assisted hydrothermal synthesis and characterization of $\mathrm{BiFeO}_{3}$ nanoparticles. J. Am. Ceram. Soc. 2007, 90, 2615-2617.

79. Chen, C.; Cheng, J.; Yu, S.; Che, L.; Meng, Z. Hydrothermal synthesis of perovskite bismuth ferrite crystallites. J. Cryst. Growth 2006, 291, 135-139.

80. Komarneni, S.; Menon, V.C.; Li, H.Q.; Roy, R.; Ainger, F. Microwave-hydrothermal processing of $\mathrm{BiFeO}_{3}$ and $\mathrm{CsAl}_{2} \mathrm{PO}_{6}$. J. Am. Ceram. Soc. 1996, 79, 1409-1412.

81. Prado-Gonjal, J.; Villafuerte-Castrejon, M.E.; Fuentes, L.; Moran, E. Microwave-hydrothermal synthesis of the multiferroic $\mathrm{BiFeO}_{3}$. Mater. Res. Bull. 2009, 44, 1734-1737.

82. Ponzoni, C.; Rosa, R.; Cannio, M.; Buscaglia, V.; Finocchio, E.; Nanni, P.; Leonelli, C. Optimization of BFO microwave-hydrothermal synthesis: Influence of process parameters. $J$. Alloys Compds. 2013, 558, 150-159.

83. Merzhanov, A.G.; Shkiro, V.M.; Borovinskaya, I.P. Synthesis of refractory inorganic compounds. US Patent 3726643, April 1973.

84. Merzhanov, A.G.; Shkiro, V.M.; Borovinskaya, I.P. Synthesis of refractory inorganic compounds. Byull. Izobr. 1971, 10.

85. Varma, A.; Lebrat, J.P. Combustion synthesis of advanced materials. Chem. Eng. Sci. 1992, 47, 2179-2194.

86. Merzhanov, A.G. Reviews: fundamentals, achievements, and perspectives for development of solid-flame combustion. Russ. Chem. Bull. 1997, 46, 1-27.

87. Morsi, K. The diversity of combustion synthesis processing: A review. J. Mater. Sci. 2012, 47, 68-92.

88. Rajeshwar, K.; de Tacconi, N.R. Solution combustion synthesis of oxide semiconductors for solar energy conversion and environmental remediation. Chem. Soc. Rev. 2009, 38, 1984-1998.

89. Nagaveni, K.; Hedge, M.S.; Ravishankar, N.; Subbanna, G.N.; Madras, G. Synthesis and structure of nanocrystalline $\mathrm{TiO}_{2}$ with lower band gap showing high photocatalytic activity. Langmuir 2004, 20, 2900-2907.

90. Selvam, N.C.S.; Kumar, R.T.; Kennedy, L.J.; Vijaya, J.J. Comparative study of microwave and conventional methods for the preparation and optical properties of novel $\mathrm{MgO}$-micro and nano-structures. J. Alloys Compds. 2011, 509, 9809-9815.

91. Nehru, L.C.; Swaminathan, V.; Sanjeeviraja, C. Rapid synthesis of nanocrystalline ZnO by a microwave-assisted combustion method. Powder Technol. 2012, 226, 29-33.

92. Rosa, R.; Ponzoni, C.; Veronesi, P.; Natali Sora, I.; Felice, V.; Leonelli, C. Solution combustion synthesis of perovskite oxides: Comparison between MWs and conventional ignition. In Proceedings of 14th International Conference on Microwave and High Frequency Heating, Nottingham, UK, 16-19 September 2013. The University of Nottingham: Nottingham, UK, 2013; pp. 250-253.

93. Kumar, A.; Wolf, E.E.; Mukasyan, A.S. Solution combustion synthesis of metal nanopowders: Nickel reaction pathways. AIChE J. 2011, 57, 2207-2214.

94. Luo, W.; Wang, D.; Peng, X.; Wang, F. Microwave synthesis and phase transitions in nanoscale $\mathrm{BiFeO}_{3}$. J. Sol-Gel Sci. Technol. 2009, 51, 53-57. 
95. Mukasyan, A.S.; Dinka, P. Apparatus and methods for combustion synthesis of nano-powders. US Patent WO2007019332-A1, February 2007.

96. Kumar, A.; Mukasyan, A.S.; Wolf, E.E. Impregnated layer combustion synthesis method for preparation of multicomponent catalysts for the production of hydrogen from oxidative reforming of methanol. Appl. Catal. A 2010, 372, 175-183.

97. Martirosyan, K.S.; Luss, D. Carbon combustion synthesis of oxides, US Patent 0097419 A1, May 2006.

98. Martirosyan, K.S.; Iliev, M.; Luss, D. Carbon combustion synthesis of nanostructured perovskites. Int. J. SHS 2007, 16, 36-45.

99. Dinka, P.; Mukasyan, A.S. In situ preparation of oxide-based supported catalysts by solution combustion synthesis. J. Phys. Chem. B 2005, 109, 21627-21633.

(C) 2014 by the authors; licensee MDPI, Basel, Switzerland. This article is an open access article distributed under the terms and conditions of the Creative Commons Attribution license (http://creativecommons.org/licenses/by/3.0/). 